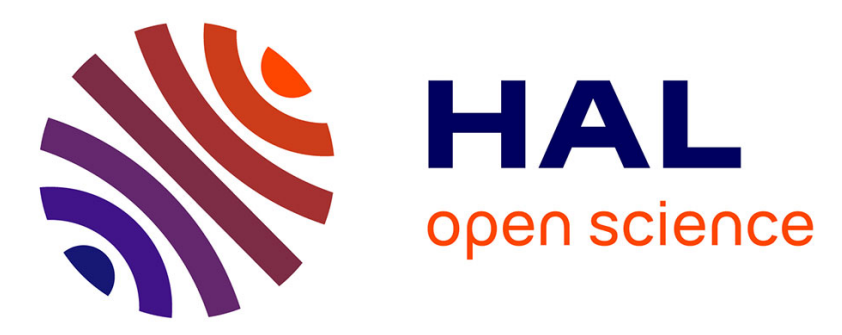

\title{
Information systems for enterprise integration, interoperability and networking: theory and applications
}

Hervé Panetto, Joe Cecil

\section{To cite this version:}

Hervé Panetto, Joe Cecil. Information systems for enterprise integration, interoperability and networking: theory and applications. Enterprise Information Systems, 2013, 7 (1), pp.1-6. 10.1080/17517575.2012.684802 . hal-00686500

\section{HAL Id: hal-00686500 \\ https://hal.science/hal-00686500}

Submitted on 1 Dec 2012

HAL is a multi-disciplinary open access archive for the deposit and dissemination of scientific research documents, whether they are published or not. The documents may come from teaching and research institutions in France or abroad, or from public or private research centers.
L'archive ouverte pluridisciplinaire HAL, est destinée au dépôt et à la diffusion de documents scientifiques de niveau recherche, publiés ou non, émanant des établissements d'enseignement et de recherche français ou étrangers, des laboratoires publics ou privés. 


\title{
Information Systems for Enterprise Integration, Interoperability and Networking: Theory and Applications
}

\author{
Hervé Panetto ${ }^{1}$ and J. Cecil ${ }^{2}$ \\ ${ }^{1}$ Research Centre for Automatic Control, University of Lorraine, CNRS, School of Engineering in \\ Information Technology, France, Herve.Panetto@univ-lorraine.fr. \\ ${ }^{2}$ Center for Information based Bioengineering and Manufacturing, School of Industrial Engineering and \\ Management, Oklahoma State University, USA, j.cecil@okstate.edu
}

\section{Introduction}

Today, enterprises can be characterized by various key facets: globalization, distributed manufacturing, data and knowledge management, advanced automation and robotics, virtual engineering, rapid response to market and more. In today's competitive economy, enterprises need collaborating using Information Technology (IT) and other tools to succeed in this dynamic and heterogeneous business environment. Enterprise integration, interoperability and networking are some of the major disciplines that are enabling companies to improve collaboration and communication in the most effective way. In this direction, the enterprise information systems engineering process aims to develop information systems to respond to increasingly complex objectives, to align these information systems with business goals and processes of the company, or simply to adapt and improve them when facing given requirements or rapidly changing opportunities. As enterprise information systems models become more ubiquitous, the sharing of best-in-class models becomes more desirable. Interoperability between dissimilar systems in sharing information is important, but other aspects are also required in the sharing of enterprise systems knowledge. First, this process is based on the need for collaboration, sharing and mutual understanding of the needs of each stakeholder i.e. each persons involved or affected by the future information system, at each stage of its development. Second, this process follows principles which highlight the need for formal semantics definition of these models to facilitate this work, at various abstraction levels ranging from specification to implementation on site. There is a need to also couple new theoretical results with applied methods and tools supporting existing business reconfiguration and transformation both locally and globally.

In this editorial, we reflect on the current and future theory and applications that would further empower networked enterprises by means of collaborative information systems. We do this inspired by the articles in this special issue, which are 6 revised extended versions (from 32 submissions) of selected best papers of the $5^{\text {th }}$ International workshop on Enterprise Integration, Interoperability and Networking (EI2N'2010), and the $18^{\text {th }}$ Cooperative Information Systems Conference (CoopIS'2010), parts of the OTM Federated Conferences, held on October 25-29, 2010 in Crete, Greece. In addition, we discuss new paradigms that may have considerable impact on Information Systems design in the context of next generation collaborative and virtual enterprises. 


\section{Enterprise Integration and Interoperability}

Enterprise integration is a domain of research developed since 1990's as the extension of Computer Integrated Manufacturing (CIM). Enterprise integration research is mainly carried out within two distinct research communities: Enterprise modelling and Information Technology (IT). The notion of Enterprise Integration as it is understood in the context of enterprise modelling refers to a range of concepts and approaches including the definition of a global architecture of the system, the consistency of systemwide decision making (coherences between local and global objectives), the notion of the process which models activity flow beyond the borders of functions, the dynamic allocation of resources as well as the consistency of data [1]. It is important to recognize that enterprise integration is an essential component of enterprise engineering which concerns the set of methods, models and tools that one can use to analyze design while achieving integration. Enterprise integration can be viewed in different integration levels according to the interest of the study. The European standardisation committee CEN TC310/WG1 has recognised three levels of integration: (1) Physical Integration (interconnection of devices, NC machines, PLCs, via computer networks), (2) Application Integration (dealing with interoperability of software applications and database systems in heterogeneous computing environments) and (3) Business Integration (co-ordination of functions that manage, control and monitor business processes). Integration can be obtained in terms of: (1) data (data modelling), (2) organisation (modelling of systems and processes) and (3) communication (modelling of computer networks, for example the 7-layer OSI model). Integration can be total, i.e. the standard is the software or system itself. Integration can be achieved by unification (the possible standards are methods, architectures, constructs and reusable partial models) or by federation (the possible standards are interfaces, reference models or ontologies).

Since the end of 1990's enterprise integration approaches have to address the emerging emphasis on 'Enterprise interoperability'. Enterprise interoperability is believed to be more adaptable (less cost and quicker implementation) in decentralised, flexible and networked system environments for product and process design environments including manufacturing. Generally, interoperability refers to coexistence, autonomy and federated environments, whereas integration refers to the concepts of coordination and coherency. From the point of view of degree of coupling, the 'tightly coupled system' indicates that the components are interdependent and cannot be separated. Therefore it is the case of an integrated system. The 'loosely coupled system' refers to the components that are connected by a communication network; they can exchange services while continuing their own logic of operation. Integration is generally considered to go beyond mere interoperability to involve some degree of functional dependence [2]. While interoperable systems can function independently, an integrated system loses significant functionality if the flow of services is interrupted. An integrated family of systems must, of necessity, be interoperable, but interoperable systems do not mean they are completely integrated. Integration also deals with organisational issues, in possibly a less formalised manner due to dealing with people, but integration is much more difficult to solve, while interoperability is more of a technical issue. Compatibility is something less than interoperability. It means that systems/units do not interfere with each other's functioning. Interoperable systems are by necessity compatible, but the converse is not necessarily true. 
Application integration concerns interoperability of applications on heterogeneous platforms. This type of integration allows access to shared data by the various remote applications. Distributed processing environments, common services for the execution environment, application program interfaces (API's), and standard data exchange formats are necessary at this level to build cooperative systems. Application integration started in the mid 1980's and is still on-going with very active work concerning STEP, EDI, HTML, XML, or eb-XML for the exchange of common shared data, development of common services for open systems around the web (web-services), integration platforms for interoperable applications in distributed environments (e.g. OSF/DCE, OMG/CORBA, WSDL, and more recently J2EE or Java to Enterprise Edition environments and .NET). Other tools used at this level are workflow management systems (WfMS) and computer support to collaborative work - CSCW [3].

\section{Enterprise Information Systems as a key feature for Enterprise Interoperability}

Business integration is considered as a key step towards the networked enterprise. Starting the physical integration at lower level to move towards business integration is typically a bottom up engineering approach. Integration at lower levels has often impacts on the business run at the higher level, thus to business integration. The process of bottom-up integration needs to be combined with a top-down global design to define consistent global enterprise architecture so that incremental bottom up integration implementation can be based on long term strategy of the company. Even when business integration has been achieved at one point in time, business opportunities, new technologies, modified legislation will make integration a vision rather than an achievable goal. In this sense, enterprise integration is also seen as a methodological process to periodically measuring the gap between desired integration goal and actual status of the system, and to adjust both the goal and integration actions if necessary [4].

Vernadat [5] defines interoperability as the ability to communicate with pier systems and access the functionality of the pier systems. Establishing interoperability means to relate two systems together and remove any incompatibilities in between. Incompatibility is a fundamental concept used in interoperability domain. It is the obstacle to establish seamless interoperation. The concept 'incompatibility' has a broad sense and is not only limited to 'technical' aspect as usually considered in software engineering, but also 'information', 'organisation' and 'semantics' [6], and concerns all levels of an enterprise. Another fundamental consideration is the generic characteristic of the interoperability research. Indeed there are generic problems and solutions regardless of the content of information exchanged between two systems. Semantic frameworks hold the potential to address interoperability issues through use of ontology. In the context of virtual enterprises, such an approach enables diverse organizations to form partnerships based on rapidly emerging market needs which are translated into new product development opportunities [7]. From another point of view and according to ISO 14258, there are three ways to develop interoperability:

- Integrated where there is a standard format for all constituent systems. Diverse models are interpreted in the standard format. This format must be as rich as the constituent system models. 
- Unified where there is a common meta-level structure across constituent models, providing a means for establishing semantic equivalence.

- Federated where models must be dynamically accommodated rather than having a predetermined meta-model. This assumes that concept mapping is done at an ontology level, i.e. semantic level.

The federated approach is seen as the most interesting one to develop full interoperability. However, the choice depends on the context and requirements. If the need of interoperability comes from a merger of enterprises, the integrated approach would be the most adapted one. If the need of interoperability concerns a long term based collaboration, the unified approach seems a good solution. For that, a common meta-model across partners' models provides a means for establishing semantic equivalence allowing mapping between diverse models. On the other hand, for a need of interoperability originated from the short-term collaboration project (e.g. virtual enterprise) the federated approach can be used. To interoperate partners must dynamically adapt to achieve an agreement [8].

An overview of the 6 papers in this special issue follows.

\section{New theory and applications for Enterprise Integration, Interoperability and Networking}

Enterprise Interoperability (EI) is a well-established area of applied research that addresses the problems related with the lack of systems and applications' interoperability in organisations, and proposes novel solutions for El problems. However, in spite of research efforts to date, the proper scientific foundations for El remain elusive. This has prevented the generalisation and full reuse of the methods and tools that have been developed so far. Jardim-Gonçalves and Grilo [9] contribute to this important issue by identifying the main characteristics related to of the scientific foundations of the Enterprise Interoperability (EI) research domain, systematizing the state of art in this domain. The recent efforts developed by this community, in developing an Enterprise Interoperability Science Foundation within the so-called "Interoperability Body of Knowledge (IBoK)" demonstrates a growing interest in developing the subject of Interoperability in a more systematic and scientific way. The study of Interoperability can be developed depending on theoretical work undertaken at three levels of essential specificity, including frameworks, theories, and models. The key research questions addressed is: How can the systematisation of IBoK contribute to the foundations of El as a science? Two hypotheses have been laid down to address the research question, namely: (1) the Enterprise Interoperability Scientific Foundation should address IBoK at the levels of frameworks, theories, and models and make a gap analysis of where current academic scientific state-of-the-art is and where it needs to go; (2) Analysis conducted at each IBoK level provides different degrees of specificity related to a particular Interoperability problem.

Franke et al. [10] propose a framework for temporal coordination of activities in dynamic situations. The domain of disaster response management is used to elaborate on the framework proposed. The author highlights the importance of this domain in light of recent disasters such as Hurrican Katrina (2005) and the Haiti Earthquakes (2010). During such disasters, the overall situation is dynamic in nature 
and the response of various teams depends largely on an understanding of the complex, dynamic situations. The framework proposed facilitates modeling activities and temporal dependencies. A part of the paper elaborates on the dynamics of the crisis management domain using a scenario example from the SoKNOS project. The author also the state of the art and concludes with some of the key limitations of the past approaches with respect to providing support for activities coordination in the context of dynamic situations. Subsequently, a discussion of the framework's implementation is provided to demonstrate technical feasibility. The paper concludes with comments of the proposed framework by disaster managers.

Through a process-lifecycle, consistency is difficult to be maintained between models from different environments. The successive developments and changes made by different stakeholders lead to the development of inconsistencies between models. A discontinuity between business perspective and IT perspective appears. Allowing the full return of a transformed model in the sense of reverse engineering, the approach outlined by Ulmer et al. [11] enables synchronization between analysis model and implementation model respectively from the business domain and IT domain. Consistency and intermodal synchronization are the necessary and sufficient conditions for an operational alignment between these domains. The authors focus their research on the "discontinuity" between the business and IT perspectives, the "business-IT gap". To improve the current alignment strategies, we suggest a generic approach for modelling and implementing processes and establish a platform that supports such an approach. We propose a method allowing the control of business processes, from their modelling to their implementation within an Information System (IS). Using concepts from the Business and IS engineering driven by models, the defined approach ensures consistency between heterogeneous models. Based on a pivotal meta-model and model, its role is to maintain and provide all information related to the structure and semantics of models. This intermediate format is considered as a reference model, necessary to store and exchange model information between modelling environments and implementation.

Hachani et al. [12] outline a service oriented approach (SOA) that facilitates design process flexibility in Product Lifecycle Management (PLM) systems. PLM systems continue to play a vital role in managing data in the life cycle of a product including design and manufacturing. It also provides the management of associated business processes that organize the creation, Business Process (BP) use and exchange of product information. They propose reusable activities as services and evolvable design processes as dynamic services composition. A three stage approach is outlined including (i) service identification using catalogues (ii) use of a services based paradigm for defining dynamic product design processes (iii) proposing alignment techniques for migration from business to technical levels. The paper's scope of emphasis is limited to the service identification stage of this multi stage approach.

Nogueira et al. [13] outline an action research methodology to assist in the implementation of an enterprise architecture framework. In the context for their approach, they view enterprise architectures as a basis to gain a better understanding of an enterprise's data. Their methodology is based on the Zachmann Framework, which is used to build an enterprise architecture which can be used to align and integrate the IT infrastructure and business objectives of technology enterprises. Based on their Action Research methodology, a case study is presented as a way to validate the benefits and feasibility of this 
methodology in a technology enterprise called PyME CREATIVA. PyME CREATIVA is a project startup with an objective of developing and integrating information technologies to build an electronic hub which in turn can be used to facilitate the creation of other virtual organizations.

Enterprise integration and interoperability frameworks have been applied in many domains. Monakova and Leymann [14] showed an original approach extending with mapping from existing process modeling standards, such as BPMN, to a model in the ART framework. They showed a business process can be visualized in 3D space, where each dimension represents a different aspect of a business process. A specification of a single workflow task was based on three main aspects: it specified what action must be done, which resources (including human resources) the task required, and in which time period it had to be executed. These three dimensions constituted the basis for the Action-Resource-Time (ART) framework.

The forthcoming $7^{\text {th }}$ EI2N'2012 workshop and CoopIS'2012 conference will be held in Rome (Italy) on September 10-14, 2012.

The Guest Editors would like to thank the Editor-In-Chief and the Associate Editor of the journal, together with all reviewers, who dedicated their valuable effort for reviewing the submitted papers; we are indebted to all of them. We also would like to thank all authors for their contribution to the special issue.

\section{References}

[1] Vernadat, F.B. (2002). Enterprise Modeling and Integration (EMI): Current Status and Research Perspectives. Annual Reviews in Control. 26, 15-25.

[2] Panetto H. (2007). Towards a Classification Framework for Interoperability of Enterprise Applications. International Journal of CIM, Taylor \& Francis, 20 (8), 727-740. ISSN: 0951-192X

[3] Goranson, T., Jochem, R., Nell, J., Panetto, H., Partridge, C., Sempere Ripoll, F., Shorter, D., Webb, P., Zelm, M. (2002). New Support Technologies for Enterprise Integration. IFIP International Conference on Enterprise Integration and Modelling Technology (ICEIMT'02), Kluwer Academics Publisher, Valencia, Spain, 24-26 April 2002, 347-358.

[4] Molina, A., Sanchez, J.M., Kusiak, A. (1999). Handbook of Life Cycle Engineering: Concepts, Models and Technologies, Kluwer Academic Press.

[5] Vernadat, F.B. (1996). Enterprise Modelling and Integration: Principles and Applications, Chapman \& Hall, London.

[6] Yahia E., Aubry A., Panetto H. (2012). Formal measures for semantic interoperability assessment in cooperative enterprise information systems. Computers in Industry, 63 (4). doi:10.1016/j.compind.2012.01.010 
[7] Cecil J., Narayanasamy G., Long J. (2011). A Semantic Framework for Distributed Nano Assembly and Engineering, On The Move to Meaningful Internet Systems, $6^{\text {th }}$ EI2N-ICE'2011 workshop on Enterprise Integration, Interoperability and Networking, Lecture Notes in Computer Science, LNCS 6428, 249-256

[8] Browne J., and Zhang J. (1999). Extended and virtual enterprises - similarities and differences, International Journal of Agile Management Systems, 1/1, 30-36

[9] Jardim-Gonçalves R., Grilo A. (2013). Systematisation of Interoperability Body of Knowledge: The foundation for El as a science, Enterprise Information Systems, 7/1, 7-32

[10] Franke J., Charoy F., El Khoury P. (2013). Framework for Coordination of Activities in Dynamic Situations. , Enterprise Information Systems, 7/1, 33-60

[11] Ulmer J.-S., Belaud J.-P., Le Lann J.-M. (2013). A pivotal-based approach for enterprise business process and IS integration. , Enterprise Information Systems, 7/1, 61-78

[12] Hachani S., Gzara L., Verjus H. (2013). A Service-Oriented Approach for Flexible Process Support within Enterprises: Application on PLM Systems. , Enterprise Information Systems, 7/1, 79-99

[13] Nogueira J. M., Romero D., Espadas J., Molina A. (2013). Leveraging the Zachman Framework Implementation Using Action-Research Methodology - A Case Study: Aligning the Enterprise Architecture and the Business Goals. , Enterprise Information Systems, 7/1, 100-132

[14] Monakova G., Leymann F. (2013). Workflow ART. , Enterprise Information Systems, 7/1, 133-166 